\title{
The Influence of Community Structure on the Diffusion of Knowledge-A View Based on Market Segmentation
}

\author{
https://doi.org/10.3991/ijet.v14i08.10397 \\ Zheng Shi-Yong \\ Wuhan University, Wuhan, China \\ Liu Mao-Hong \\ Wuhan University of Science and Technology, Wuhan, China \\ Huang Jin-De $(\bowtie)$ \\ Guangxi College of Education, Nanning, China \\ $229292710 @$ gq.com
}

\begin{abstract}
To analyze the effects of different seeding selection strategies on knowledge diffusion in education field, this study builds an ABMS spreading model and performs several simulation experiments. Besides, market segmentation is proposed as the methods of community recognition as, the effects of the mechanism of market segmentation on seeding user choosing strategies are investigated, and knowledge diffusion efficiency is analyzed. Given the existing education community structure in social network of knowledge, and the formation mechanism of network, and even if the multiple seeds locate in the same education community, they cannot effectively exert the knowledge diffusion function of each seeding node. Several studies have showed that random selection strategy is more effective than the sensitive strategy without any market segmentation. The seeding strategy integrated with market segmentation is capable of improving the efficiency of knowledge diffusion significantly. In the meantime, the sensitive seeding strategy under the education community recognition can achieve better knowledge diffusion efficiency.
\end{abstract}

Keywords-Market segmentation; community recognition; seeds; knowledge diffusion

\section{Introduction}

Education innovation emphasizes not only on knowledge development, but also on the knowledge diffusion process. In the mass media era, consumers lack a timely and efficient interactive platform. Education enterprises face difficulties in building interactive networks between consumers or scholar. The social media has changed the way users interact with each other, which is vital for the education enterprise and for marketing. Besides, it brings new challenges to education management. 
The market segmentation based on the statistical characteristics for individual users in the transaction mode employs a top-down standardization stimulus, which contributes to implementing colony-marketing strategies via the mass media to obtain scale economies effect. This group based on individual attribute division ignores the association between users, whereas users gather to form community groups in the social media environment, and users in the community are closely linked. As shown in Fig. 1 , in a community platform, users can fall into groups with similar characteristics in line with the vertical segmentation of transactions, and the communities can be divided according to the horizontal interaction between users.

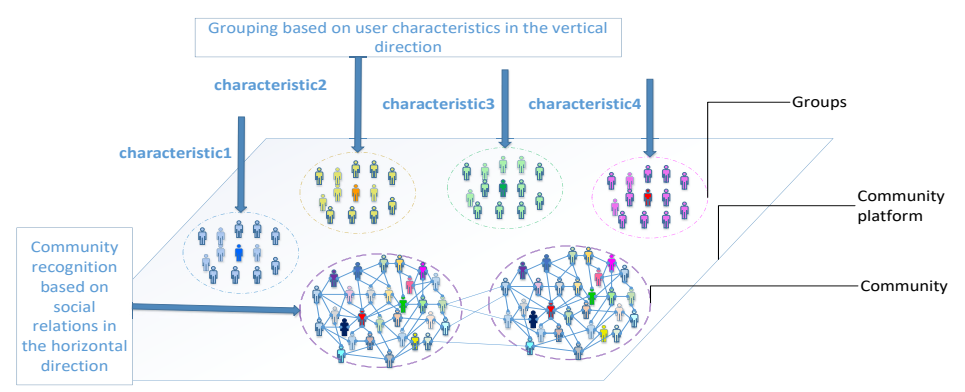

Fig. 1. Group and Community in community platform

Whether to consider the association between users reflects the difference between groups and communities. The differences in the marketing strategies between the two are presented in the table below. Studies have shown that the network by user interactions in the horizontal direction instinctively excludes advertising from companies in the vertical direction. Accordingly, market segmentation (groups) based on individual attributes does not contribute to the information dissemination and diffusion.

Table 1. Group marketing and community marketing

\begin{tabular}{|l|l|l|}
\hline \multicolumn{1}{|c|}{ Compared content } & Vertically segmented group marketing & $\begin{array}{l}\text { Horizontally associated commu- } \\
\text { nity marketing }\end{array}$ \\
\hline Within the market segment & Homogeneous users & $\begin{array}{l}\text { Coexistence of homogeneous and } \\
\text { heterogeneous users }\end{array}$ \\
\hline Outside the market segment & Segmentation market heterogeneity & Similarity between communities \\
\hline Segment market users & Ignoring relationships between users & $\begin{array}{l}\text { Considering relationships between } \\
\text { users }\end{array}$ \\
\hline Subdivision criteria & Individual user statistical characteristics & User relations, network structure \\
\hline Subdivision criteria & User statistics feature is relatively static & $\begin{array}{l}\text { Dynamic evolution in user associa- } \\
\text { tions }\end{array}$ \\
\hline Send message & $\begin{array}{l}\text { High information accuracy, many steps, } \\
\text { long cycle }\end{array}$ & $\begin{array}{l}\text { Arbitrary information, fewer steps, } \\
\text { faster updates }\end{array}$ \\
\hline Segmentation perspective & Economic scale perspective & $\begin{array}{l}\text { Information communication per- } \\
\text { spective }\end{array}$ \\
\hline
\end{tabular}

*Source: collated by our study

Besides, the study of innovative diffusion seed selection strategies focuses on the node individual's sensitivity, e.g. the seed users' level, seed size, and seed network 
properties (intermediary centroid, K-core coefficient, near-centrality). However, these strategies ignore the aggregation effects between seed nodes, aggregation of multiple child nodes and common user nodes, as well as the division of aggregation on knowledge/information diffusion. Thus, this study lays the emphasis on the regulation effect of market segmentation on seed nodes selection and the effect on the diffusion effect. Since the information dissemination is closely associated with the seed influence/sensitivity, companies prefer seed users with more sensitive users such as opinion leaders. Accordingly, when studying the node's effects, this study employed node size to represent the node sensitivity while controlling other sample network properties.

Table 2. Research on the products or knowledge dissemination influence based on complex networks

\begin{tabular}{|c|c|c|c|c|c|c|}
\hline Literature & $\begin{array}{c}\text { Network } \\
\text { type }\end{array}$ & $\begin{array}{c}\text { Seed } \\
\text { strategy }\end{array}$ & $\begin{array}{l}\text { Model / } \\
\text { method }\end{array}$ & Information & $\begin{array}{l}\text { Seed } \\
\text { scale }\end{array}$ & Variable \\
\hline $\begin{array}{l}\text { (Bass } \\
2004)\end{array}$ & $\begin{array}{l}\text { random } \\
\text { network }\end{array}$ & Hub & $\begin{array}{l}\text { Bass } \\
\text { Model } \\
\end{array}$ & Product & Individual & Volume \\
\hline $\begin{array}{l}\text { (D et al. } \\
2005)\end{array}$ & $\begin{array}{l}\text { WS Small } \\
\text { world } \\
\text { network }\end{array}$ & Hub & $\begin{array}{l}\text { Rumor } \\
\text { Model }\end{array}$ & Rumor & Individual & Scope \\
\hline $\begin{array}{l}\text { (Garcia } \\
\text { 2005) }\end{array}$ & $\begin{array}{l}\text { Social } \\
\text { networks }\end{array}$ & $\begin{array}{l}\text { Hub/Betwe } \\
\text { enness } \\
\text { Centrali- } \\
\text { ty/k-core }\end{array}$ & $\begin{array}{l}\text { SIR/SIS } \\
\text { Model }\end{array}$ & Epidemic & Individual & Scope \\
\hline $\begin{array}{l}\text { (Q et al. } \\
2005)\end{array}$ & $\begin{array}{l}\text { BA Scale- } \\
\text { free net- } \\
\text { work }\end{array}$ & $\begin{array}{l}\text { Hub/Close } \\
\text { ness Cen- } \\
\text { trality }\end{array}$ & $\begin{array}{l}\text { A Viral } \\
\text { Branching } \\
\text { Model }\end{array}$ & $\begin{array}{l}\text { Word-of- } \\
\text { mouth }\end{array}$ & Individual & Scope \\
\hline $\begin{array}{l}\text { (Nguyen } \\
\text { and Shi } \\
\text { 2006) }\end{array}$ & $\begin{array}{l}\text { Social } \\
\text { networks }\end{array}$ & $\begin{array}{l}\text { Hub/Betwe } \\
\text { enness } \\
\text { Centrality }\end{array}$ & $\begin{array}{l}\text { Conditional } \\
\text { probability } \\
\text { model }\end{array}$ & Product & Individual & Volume \\
\hline $\begin{array}{l}\text { (Delre et } \\
\text { al. 2007) }\end{array}$ & $\begin{array}{l}\text { Small } \\
\text { world } \\
\text { network }\end{array}$ & $\begin{array}{l}\text { Hub/Betwe } \\
\text { enness } \\
\text { Centrality }\end{array}$ & $\begin{array}{l}\text { Cellular } \\
\text { Automata }\end{array}$ & Product & Individual & Scope \\
\hline (Lee 2012) & $\begin{array}{l}\text { BA Scale- } \\
\text { free net- } \\
\text { work }\end{array}$ & Hub & $\begin{array}{l}\text { ABMS: } \\
\text { pi(t) }=1- \\
(1-d i)(1- \\
\text { qi)Ni(t) }\end{array}$ & Product & Individual & Volume \\
\hline $\begin{array}{l}\text { In this } \\
\text { paper }\end{array}$ & $\begin{array}{l}\text { Social } \\
\text { networks }\end{array}$ & $\begin{array}{l}\text { Hub/rando } \\
\mathrm{m} / \mathrm{cluster} / \mathrm{c} \\
\text { ommunity }\end{array}$ & $\begin{array}{l}\text { ABMS } \\
\text { aseon Bass } \\
\text { and SIR }\end{array}$ & Knowledge & $\begin{array}{l}\text { Commu- } \\
\text { nity } \\
\text { group } \\
\end{array}$ & $\begin{array}{l}\text { Scope/time } \\
\text { /efficiency }\end{array}$ \\
\hline
\end{tabular}

*Source: collated by our study

The user interaction influence on knowledge/information diffusion is stratified into two levels, namely macro and micro. The macro-level focuses on the global network effects. The Bass model is considered the most influential diffusion model, while the micro-level focuses on individual user behaviors (e.g. Cellular Automata). The complex networks show that the community structure is a meso-scale between macroscopic and microscopic aspect, and its external features are revealed in the similarities between communities and network iterations. Its internal characteristics are reflected in the interactivity between individual users. 
Thus, this study follows this research idea. The user interaction effects and market segmentation mechanisms on the knowledge/information diffusion efficiency were simulated and analyzed here from the perspective of the community in the network. Subsequently, community identification was discussed as a market. Subdividing methods, combined with the seed selection strategy for community identification, can promote the knowledge/information diffusion efficiency and discuss the community structure for enterprises in formulating knowledge/information diffusion strategies.

\section{Research Methods and Basic Models}

\subsection{Sample selection}

The data originated from the forwarding and gift-giving activities initiated by a company's Weibo account. The data here were collected on the user's fans that participated in the activity and users using crawling software. Moreover, a social network was built. User node information and network parameters are listed in Table 3.

Table 3. User node information

\begin{tabular}{|l|l|l|}
\hline \multicolumn{1}{|c|}{ Data name } & \multicolumn{1}{c|}{ Data interpretation } & \multicolumn{1}{c|}{ Data Format } \\
\hline Member ID & Weibo user ID & Text type \\
\hline Member nickname & Weibo users' network aliases & Text type \\
\hline $\begin{array}{l}\text { Number of mem- } \\
\text { bers }\end{array}$ & $\begin{array}{l}\text { The number of users who are follow- } \\
\text { ing the member }\end{array}$ & Numerical type \\
\hline Member attention & $\begin{array}{l}\text { The number of members who are follow- } \\
\text { ing the member }\end{array}$ & Numerical type \\
\hline Microblogs & The number of microposts sent by this member & Numerical type \\
\hline User level & Weibo user activity index & Numerical type \\
\hline Location & User location information when registering & Text type \\
\hline Gender & User's registered gender & Text type \\
\hline Registration time & When users sign up for a Sina Weibo account & Date type \\
\hline Homepage & Sina Weibo personal space link address & URL \\
\hline
\end{tabular}

Table 4. Network parameters

\begin{tabular}{|l|c|l|}
\hline \multicolumn{1}{|c|}{ Network structure } & Index statistics & \multicolumn{1}{c|}{ Explanation of indicators } \\
\hline Number of nodes & 4263 & $\begin{array}{l}\text { Number of members in the network that are related to each } \\
\text { Edge }\end{array}$ \\
\hline Average & 14.074 & Average associations number in network members \\
\hline Network diameter & 8 & The furthest distance between any two members in the network \\
\hline Figure density & 0.003 & Number of connections already existing between members \\
\hline Average path length & 4.14212 & $\begin{array}{l}\text { The average distance the information needs to travel between } \\
\text { any two members }\end{array}$ \\
\hline
\end{tabular}




\begin{tabular}{|l|c|l|}
\hline Modularity & 0.68 & $\begin{array}{l}\text { Measure the community quality ,the closer to 1, the stronger the } \\
\text { community structure }\end{array}$ \\
\hline $\begin{array}{l}\text { Average clustering } \\
\text { coefficient }\end{array}$ & 0.169 & A factor describing the degree of member aggregation \\
\hline $\begin{array}{l}\text { Community division } \\
\text { number }\end{array}$ & 8 & The number of communities in the network \\
\hline
\end{tabular}

\subsection{Community division}

In the present study, fast non-overlapping community recognition algorithms were employed to divide the network into 8 communities. The community division is illustrated in the figure below.
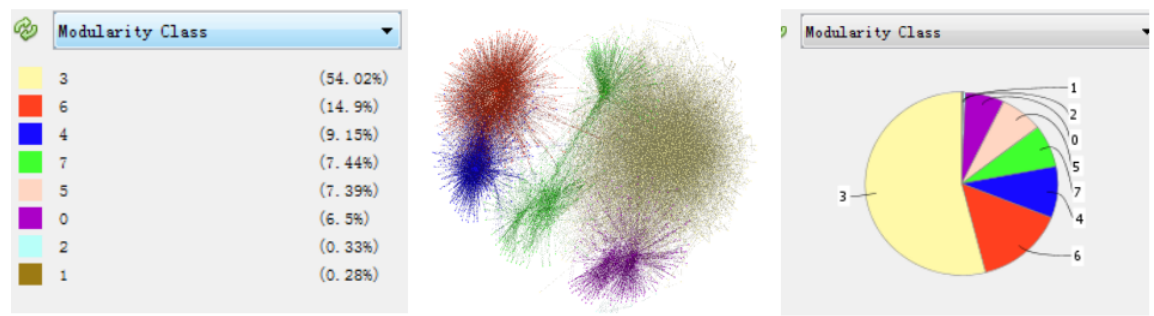

Fig. 2. Community division

\subsection{Cluster analysis}

The sample attributes here include the number of followers, the number of followers, the number of postings, interests, registration time, user ratings and place of birth. The number of fans served as a sensitivity indicator to select the seed node for sensitivity. In the cluster analysis, the user's social tag, user rating, was adopted as the clustering criteria. To effectively compare with community recognition, users were divided into 8 market segments by user level.

\subsection{Propagation and diffusion model}

Based on the Bass diffusion model and the epidemic propagation model SIR, this study uses Python to develop an ABMS propagation diffusion model for testing propagation effects under different seed strategies. When using it, it is necessary to input the adjacency matrix csv for the specified network. The file and the seed user list can return the transmission length (path length) and the transmission rate. In the case with a $100 \%$ transmission rate, the shorter the propagation path and the less time consuming, the better the diffusion effect is.

In the ABMS model used in this study, the three nodes status in the epidemic propagation model SIR are introduced. The susceptible value is 0 , which refers to users in the network that have not yet acquired information; Seed nodes/infected (infected) 
values A value is 1 refers to a user who has acquired information and has a spread in the network; A recovered value is -1 refers to a user who once had a propagation function (who used to be a seed node) but who no longer has a propagation function. In the propagation process, nodes only interact with nodes that are directly related to themselves. Each node has two status changes: The first is that an uninfected seed becomes a seed user after being infected by an adjacent seed user, and the node status value changes from 0 to 1 . Alternatively, when there are no uninfected users in the seed users' neighboring nodes, the seed users become immunized and the node status value changes from 1 to -1 .

At the same time, three prediction parameters in the Bass propagation model are introduced.

- P--external influence coefficient, that is, the probability that non-infected persons receiving influence from external factors. According to the robustness in a complex network, the anti-jamming performance is proportional to the node degree. Therefore, the impact of external information stimuli on a node is negatively related to the node degree. The interference immunity for node $\mathrm{i} i \mathrm{is} \frac{\mathrm{DG}_{\mathrm{i}}}{\max \left(\mathrm{DG}_{\mathrm{n}}\right)}$, where $\mathrm{DG}_{\mathrm{i}}$ is the degree of node i,max $\left(D_{n}\right)$ represents the maximum node degree in a network with $\mathrm{n}$ nodes. The probability that external information stimulating the impact on node $i$ is

$$
\mathrm{P}=1-\frac{\mathrm{DG}_{\mathrm{i}}}{\max \left(\mathrm{DG}_{\mathrm{n}}\right)}
$$

- Q--internal influence coefficient, that is, the probability that non-infected seeds are affected by neighboring seed nodes. If there are more seed nodes in adjacent nodes $\mathrm{i}$, then the probability that node $\mathrm{i}$ being infected is greater.

$$
\mathrm{Q}=\frac{\mathrm{SD}_{\mathrm{i}}}{\mathrm{DG}_{\mathrm{i}}}
$$

Where $\mathrm{SD}_{\mathrm{i}}$ is the number of seed nodes in the adjacent node $i$; $D G_{i}$ is the degree of node i.

- N--The total number of all potential users, that is, the total number of nodes in the network.

Through the above analysis, the probability that the node is not affected by the external information is $1-\left(1-\frac{\mathrm{DG}_{\mathrm{i}}}{\max \left(\mathrm{DG}_{\mathrm{n}}\right)}\right)$, the probability that the node is not affected by the internal information is $1-\frac{\mathrm{SD}_{\mathrm{i}}}{\mathrm{DG}_{\mathrm{i}}}$, then the node is affected both internally and externally, and the probability that the uninfected susceptible becomes infected $R_{S_{-} i}$ is

$$
\begin{array}{r}
\mathrm{R}_{\mathrm{S}_{-} \mathrm{i}}=1-(1-\mathrm{P}) *(1-\mathrm{Q})^{\mathrm{S}_{\mathrm{i}}} \\
\mathrm{R}_{\mathrm{S}_{-} \mathrm{i}}=1-\left(1-\left(1-\frac{\mathrm{DG}_{\mathrm{i}}}{\max \left(\mathrm{DG}_{\mathrm{n}}\right)}\right)\right) *\left(1-\frac{S \mathrm{~S}_{\mathrm{i}}}{D \mathrm{G}_{\mathrm{i}}}\right)^{S \mathrm{~S}_{\mathrm{i}}}
\end{array}
$$


During the propagation process, the algorithm flow chart is as shown below:

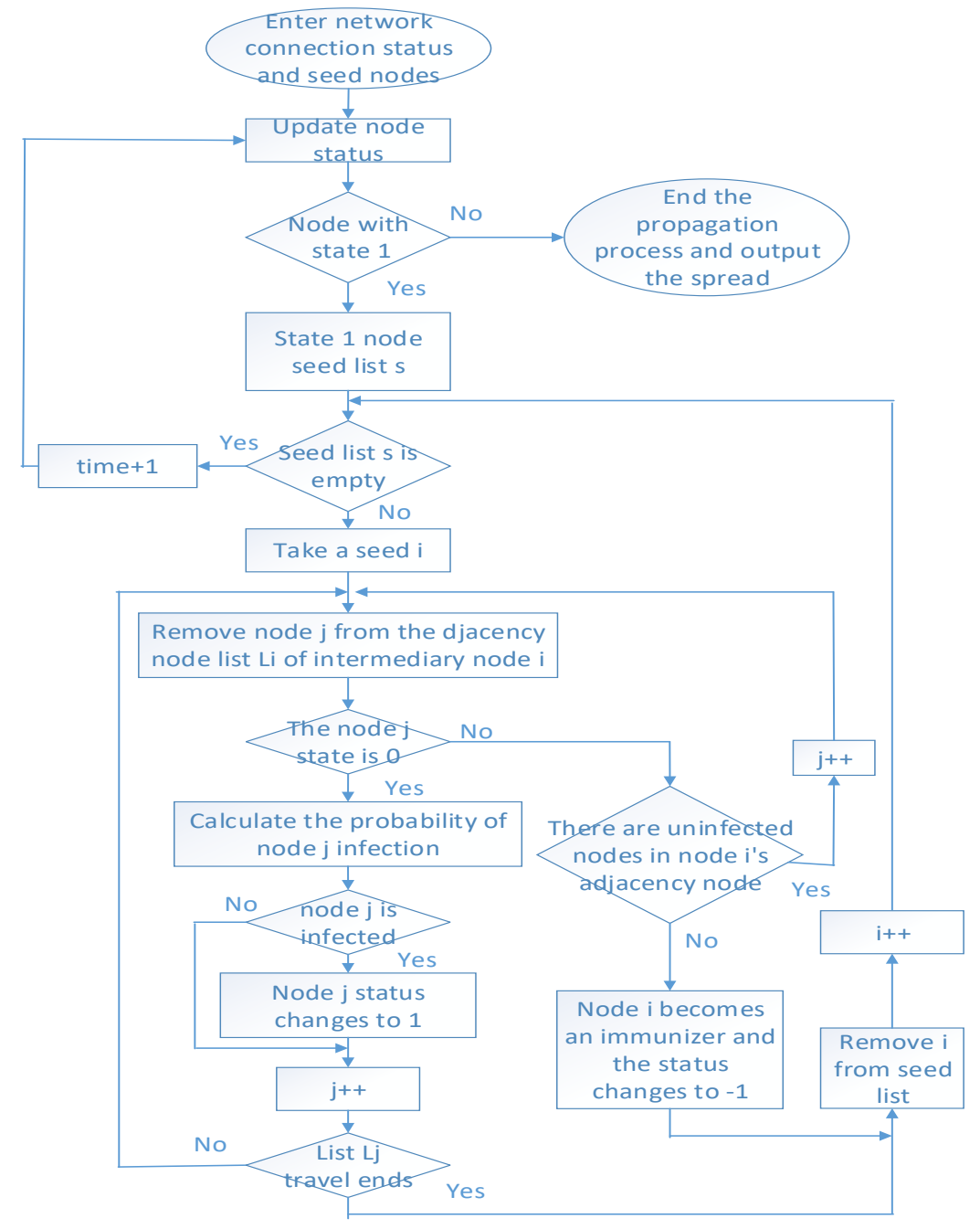

Fig. 3. Diffusion model algorithm flow

When the propagation process is over, the output diffusion information includes the ratio for the immunization population in all propagation coverage rate nodes), the propagation time (the number of all seed nodes spreading), and the propagation efficiency. Then,

$$
\text { Efficiency }=\frac{\text { Scope }}{\text { Time }}
$$




\section{Simulation Experiments and Research Results}

Due to the need for multiple combining seed stimulation during the experiment, it is likely to stimulate the same seed multiple times. Operating in a realistic environment may make the subject contaminated, thereby leading to distorted data. Besides, since we use real network samples and use probability functions when information dissemination, it is necessary to iterate multiple times to ensure the data stability and validity when performing random selection. Accordingly, repeated stimulation iterations cannot be performed on actual users. Thus, simulation experiment method and the ABMS model were used here to simulate the information diffusion process. To obtain more accurate diffusion effect data, 5,000 iterations were performed for each sample group and averaged the diffusion results to verify the correlation between the sample group and diffusion effects. The simulation diffusion process is shown in the figure below. Fig. 4a shows the initial state and Fig. 4b shows the mid-diffusion period. The red node indicates that the seed node/infected value is 1 , the green node indicates that the susceptible value is 0 , the blue node indicates that the recovered value is -1 , and the yellow node indicates that the spread is spreading.
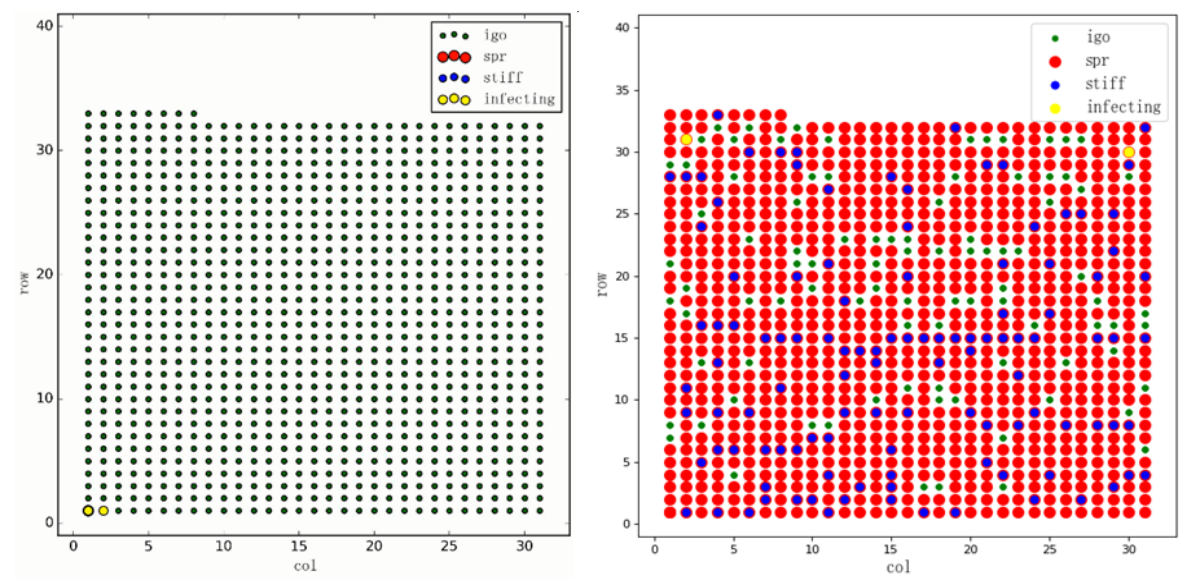

Fig. 4. Diffusion simulation process

\subsection{Experiment 1 Effect of seed quantity and sensitivity on knowledge / information diffusion efficiency}

In Experiment 1A, 50 seed nodes with the same sensitivity were selected to form a seed pool PL. In the first group, a seed was randomly selected from the PL and transmitted as a sample group il to obtain the range $\mathrm{S}$, time $\mathrm{T}$ and efficiency $\mathrm{E}=\mathrm{S} / \mathrm{T}$ of propagation. The experiment was repeated 5,000 times for the first group, and the efficiency E was obtained. E (i1) was obtained from the mean E. From the PL, randomly select 2, 3, 30 seeds, and the above experiment was repeated to obtain the transmission efficiency E (i1), E (i2), E (i30) for each sample group. The Pearson 
correlation coefficient between the number of sample points $\mathrm{N}$ and the propagation efficiency $\mathrm{E}$ (iN) was calculated.

Table 5. Relevance and descriptive statistics $(\mathrm{N}=30)$

\begin{tabular}{|c|c|c|c|c|c|}
\hline & $\begin{array}{c}\text { N(Pearson/ } \\
\text { Significance) }\end{array}$ & $\begin{array}{c}\text { T(Pearson/ } \\
\text { Significance) }\end{array}$ & $\begin{array}{c}\text { E(Pearson/ } \\
\text { Significance) }\end{array}$ & $\begin{array}{c}\text { Mean } \\
\text { Value }\end{array}$ & $\begin{array}{c}\text { Standard } \\
\text { Deviation }\end{array}$ \\
\hline $\mathrm{N}$ & 1 & $-.924 * * / .000$ & $.960 * * / .000$ & 15.5000 & 8.80341 \\
\hline $\mathrm{S}$ &. $\mathrm{a}$ &. $\mathrm{a}$ &. $\mathrm{a}$ & 1.0000 & .00000 \\
\hline $\mathrm{T}$ & $-.924 * * / .000$ & 1 & $-.994 * / .000$ & 6.2110 & .63607 \\
\hline $\mathrm{E}$ & $.960 * * / .000$ & $-.994 * * / .000$ & 1 & .1625 & .01511 \\
\hline
\end{tabular}

**. Significant correlation at level .01

\section{$\mathrm{E} / \mathrm{N} \quad \mathrm{S}=1$}

0.2

\section{Efficiency= Scope/time}

\subsection{5}

0.1

Fig. 5. Experiment results for $1 \mathrm{~A}$

The Pearson correlation coefficients for the variables N, S, T, and E are listed in Table *. Since each diffusion range covers the entire network, $\mathrm{S}$ is a constant 1 . The correlation coefficient between the nodes number and propagation time $\mathrm{T}$ is -0.924 , and the correlation coefficient with propagation efficiency is 0.96 , suggesting that the nodes number is negatively associated with the propagation time and positively related to the propagation efficiency, and the relationship coefficient is significant at $1 \%$. This reveals that the more seed nodes, the more conducive to the information propagation.

In Experiment 1B, 20 seed nodes with different sensitivities were selected to form a seed pool PL. In the first group, a seed il was randomly selected from the PL to transmit and the propagation range $\mathrm{S}$, time $\mathrm{T}$, and propagation efficiency $\mathrm{E}=\mathrm{S} / \mathrm{T}$ were obtained. The experiment was repeated 5000 times for the seed i1, and the efficiency E was averaged to obtain E (I1), at the same time, remove il from the PL. From the PL, i2, i3...i15 are taken randomly, for a total 15 different seeds. Repeat the above experiment to obtain the propagation efficiency E(i1), E(i2),..E(i15) for each seed, 
and examine the Pearson correlation coefficient of each sensitivity $\mathrm{D}(\mathrm{iN})$ and propagation efficiency $\mathrm{E}(\mathrm{iN})$ : The following descriptive statistics and relationship coefficient matrix are obtained:

Table 6. Relevance and descriptive $(\mathrm{N}=15)$

\begin{tabular}{|c|c|c|c|c|c|}
\hline variable & $\begin{array}{c}\text { D(Pearson/Signi } \\
\text { ficance) }\end{array}$ & $\begin{array}{c}\text { T(Pearson/Signi } \\
\text { ficance) }\end{array}$ & $\begin{array}{c}\text { E(Pearson/Signi } \\
\text { ficance) }\end{array}$ & $\begin{array}{c}\text { Mean } \\
\text { Value }\end{array}$ & $\begin{array}{c}\text { Standard } \\
\text { Deviation }\end{array}$ \\
\hline $\mathrm{D}$ & 1 & $-.896^{* *} / .000$ & $.914 * * / .000$ & 86.4000 & 62.84198 \\
\hline $\mathrm{S}$ & $\mathrm{a}$ &. $\mathrm{a}$ &. $\mathrm{a}$ & 1.0000 & .00000 \\
\hline $\mathrm{T}$ & $-.896 * / .000$ & 1 & $-.998 * * / .000$ & 8.3760 & .50751 \\
\hline $\mathrm{E}$ & $.914 * * / .000$ & $-.998 * * / .000$ & 1 & .1198 & .00701 \\
\hline
\end{tabular}

**. Significant correlation at level .01

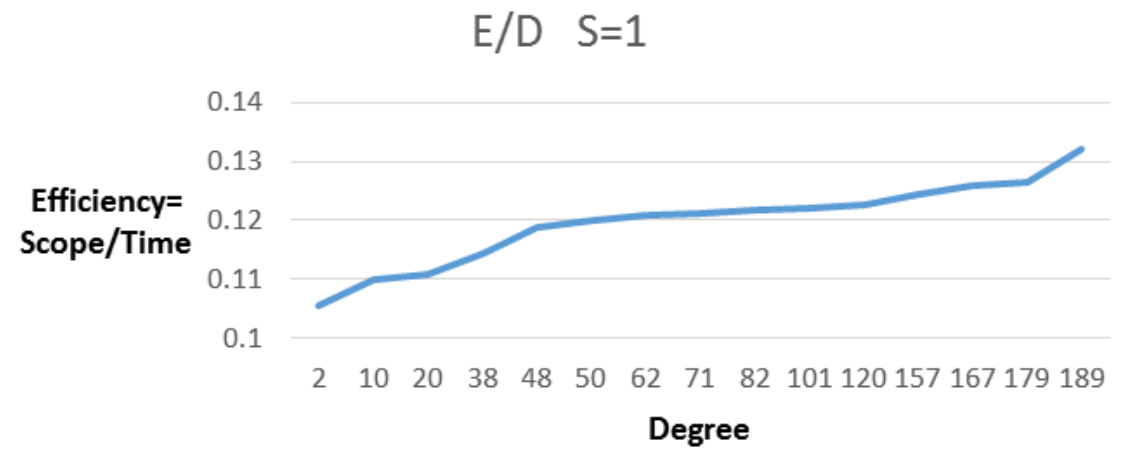

Fig. 6. Experiment results for $1 \mathrm{~B}$

The table * lists the Pearson correlation coefficients for the D, S, T, and E. The correlation coefficient between node $\mathrm{D}$ and propagation time $\mathrm{T}$ is -0.896 , and the correlation coefficient with propagation efficiency E is 0.914 , suggesting that the node degree is negatively correlated with propagation time and positively associated with propagation efficiency, and the relationship coefficient is significant at $1 \%$ level. This explains that the node with a large selection degree serves as a seed, which is more conducive to the information propagation.

Conclusion 1 The seeds number is positively associated with the transmission efficiency, and the seed sensitivity is positively related to the transmission efficiency.

\subsection{Experiment 2 Differences in knowledge/information diffusion efficiency between random seed selection strategies and sensitive seed selection strategies}

Several studies showed that node similarity is a key factor in forming a connection. Node similarity includes both node individual characteristics and node network characteristics. When nodes' individual characteristics are not considered, nodes with similar network characteristics are more likely to establish connections. With the 
expansion of the scaled network, the network will experience "new node connection first, and later connection to old nodes." Edge acceleration will occur, namely the initial phase in network construction will reflect matching, and the network maturity will reflect heterogamy. Thus, during the evolution of the network, nodes with the same scale are likely to be connected to each other and located in the same community. Previous research on seed selection showed that the seeds sensitivity is conducive to improving diffusion efficiency. This conclusion has been verified in Experiment 1. If several nodes selection with the highest sensitivity is simultaneously used as a seed, if is it more conducive to knowledge/information diffusion? We conducted the Experiment 2.

In experiment 2 , the seed pool PL consisted of 4263 nodes. When randomly selecting points, one node randomly selected from the PL served as the sample group i1 to propagate, and the il propagation range $S$, time $T$, and propagation efficiency $E=S / T$ were obtained. I1 repeated the experiment 5000 times, and the transmission efficiency was averaged to obtain the efficiency ER (i1). 2-30 nodes were randomly extracted from the PL, as sample group i2-i30. The above experiment was repeated to obtain the propagation efficiency ER (iN) of each sample group iN.

When sensitivity point was selected, the sensitivity of all nodes was ranked first. The node with the highest selectivity degree served as the sample group il for propagation. The il propagation range $\mathrm{S}$, time $\mathrm{T}$, and propagation efficiency $\mathrm{E}=\mathrm{S} / \mathrm{T}$ were obtained. The experiment was repeated 5,000 times. The transmission efficiency was averaged to get ES (i1). 2-30 nodes were randomly extracted from the PL, as sample group i2-i30. The above experiment was repeated to obtain the propagation efficiency Es(iN) of each sample group iN.

For the seeds number from 1-30, ER and ED were paired for $\mathrm{T}$ test, the following statistical information was obtained:

Table 7. Paired sample statistics and test results $(\mathrm{N}=30)$

\begin{tabular}{|l|c|c|c|c|c|}
\hline & $\begin{array}{c}\text { Mean } \\
\text { Value }\end{array}$ & $\begin{array}{c}\text { Standard } \\
\text { Deviation }\end{array}$ & t & df & Sig \\
\hline ER - ES & .02751746700 & .01503435490 & 10.025 & 29 & .000 \\
\hline ER random selection & .1691784527 & .01931749562 & & & \\
\hline ESno sensitive selection points & .1416609857 & .00473966734 & & & \\
\hline
\end{tabular}

The original hypothesis is significant at the $1 \%$ level, suggesting that there is a significant difference in the dissemination efficiency for the 2 election strategies. From the mean sample statistics, there existed no difference between the ER random selection more than ES and no sensitive selection points. This suggests that the transmission efficiency of non-differential random selection is higher than the average transmission efficiency of non-divided sensitive selection. Previous studies on seed strategy suggested that selecting a node with high sensitivity as a seed is more conducive to knowledge/information diffusion when multiple seeds are spread. Studies have shown that the more dispersed the distribution for seed nodes, the more conducive it will be to the information dissemination. This study analyzed the results of community recognition and found that the most sensitive nodes are in the same community. At this point, if a few nodes with the highest sensitivity are selected as seeds, the seed 
nodes are to be clustered within a small area (in the same community), which does not contribute to knowledge/information diffusion.

Conclusion 2 When the most sensitive nodes in the network locate in the same community simultaneously, random selection can make the seeds distribution more dispersed, which is more conducive to the information dissemination.

\subsection{Experiment 3 Effect of market segmentation on knowledge/information diffusion}

In Experiment 2, it was confirmed that the seeds aggregation is not conducive to knowledge/information diffusion. Subsequently, when selecting seeds, the selection of multiple seeds in the same node set can be avoided if the nodes aggregation can be identified. In the STP strategy, market segmentation is a collection for users. Thus, we conducted the Experiment 3 to solve the problems that whether the market segmentation mechanism is conducive to seed selection and knowledge/information diffusion, and which market segmentation method is more conducive to knowledge/information diffusion.

To divide the community, non-overlapping community recognition algorithms were employed to divide all nodes into 8 communities. When clustering was performed, all nodes were divided into 8 clusters according to the node hierarchical attributes. Under the two market segments, eight market segments was obtained.

The seed number in each market segment is determined as N: If the total seed number is $N_{\text {total }}$, the seed number for each market segment is $N_{\text {base }}=N_{\text {total }} / 8$; if $N_{\text {add }}=N_{\text {total }} \% 8$, and $N_{\text {add }} \neq 0$, a market segment is randomly selected in the eight market segments, the number is $N_{\text {add }}$, the seed number is $N_{\text {base }}+1$; for the remaining segments, the seed number is $N_{\text {base }}$.

Experiment 3.1, random selection after community identification. Under the total seed number of $N_{\text {total }}$, calculate the seeds number $\mathrm{N}$ in each market segment and randomly select $\mathrm{N}$ nodes in each community as seeds for propagation. Under the range $\mathrm{S}$, time $\mathrm{T}$, and efficiency $\mathrm{E}=\mathrm{S} / \mathrm{T}$, the propagation was repeated 5000 times. The mean transmission efficiency, the total seed number $N_{\text {total }}$ for the transmission efficiency is Ecommunity_R $N_{\text {total }}$. The value ranged from 1-30 for $N_{\text {total }}$, and Ecommunity_R(1), Ecommunity_R(2),...Ecommunity_R(30) were calculated.

Experiment 3.2, the community identification and sensitive selection. Under the total seed number of $N_{\text {total }}$, calculate the number N in each market segment, select the $\mathrm{N}$ nodes with the highest sensitivity in the community as seeds for propagation, and obtain the range $\mathrm{S}$, time $\mathrm{T}$ and efficiency $\mathrm{E}=\mathrm{S} / \mathrm{T}$ of propagation. The experiment was repeated 5000 times, and the mean transmission efficiency was obtained. The total seed number is $N_{\text {total }}$, and the transmission efficiency is Ecommunity_S (). The value ranged from 1-30, and Ecommunity_S (1), Ecommunity_S(2),...Ecommunity_S(30) were calculated. 
Experiment 3.3, random selection after cluster analysis. Under the total seed number of $N_{\text {total }}$, calculate the number $\mathrm{N}$ in each market segment and randomly select $\mathrm{N}$ nodes in the cluster as seeds for propagation. The range $\mathrm{S}$, time $\mathrm{T}$ and efficiency $\mathrm{E}=\mathrm{S} / \mathrm{T}$ of propagation are repeated. The experiment was repeated 5000 times, the mean transmission efficiency was obtained by the total seed number as the propagation efficiency Ecluster_R( ). The value ranged from 1-30, and Ecluster_R(1), Ecluster_R(2),...Ecluster_R(30) were calculated.

Experiment 3.4, sensitive selection after cluster analysis. Under the total seed number of $N_{\text {total }}$, calculate the number $\mathrm{N}$ in each market segment, and select the $\mathrm{N}$ nodes with the highest sensitivity as the seeds for propagation in the cluster to obtain the range $\mathrm{S}$, the time $\mathrm{T}$ and the efficiency $\mathrm{E}=\mathrm{S} / \mathrm{T}$ of propagation. The experiment was repeated 5000 times. The mean of propagation efficiency was obtained, and the total seed number was the propagation efficiency Ecluster_S (). The value ranged from 130, and Ecluster_S (1), Ecluster_S (2), Ecluster_S (30) were calculated.

In accordance with the above experimental results, the ER, ES, Ecommunity_R, Ecommunity_S, Ecluster_R, and Ecluster_S were tested for multiple correlation samples in the non-parametric test to acquire the following statistical information:

Table 8. Sample statistics and multi-sample test results $(\mathrm{N}=30)$

\begin{tabular}{|l|c|c|c|c|c|}
\hline & $\begin{array}{c}\text { minimal } \\
\text { value }\end{array}$ & $\begin{array}{c}\text { maximal } \\
\text { value }\end{array}$ & $\begin{array}{c}\text { Mean } \\
\text { Value }\end{array}$ & $\begin{array}{c}\text { Standard } \\
\text { Deviation }\end{array}$ & Rank mean \\
\hline Seed_number & 1 & 30 & 15.50 & 8.803 & 3.13 \\
\hline $\begin{array}{l}\text { ER no partition random } \\
\text { selection }\end{array}$ & .11792453 & .19157088 & .1691784527 & .01931749562 & 1.30 \\
\hline $\begin{array}{l}\text { ES no partition random } \\
\text { selection }\end{array}$ & .12300123 & .14947683 & .1416609857 & .00473966734 & 3.83 \\
\hline $\begin{array}{l}\text { Ecommunity_R commu- } \\
\text { nity identification random } \\
\text { selectio }\end{array}$ & .11764706 & .19267823 & .1706796970 & .01927568955 & \\
\hline $\begin{array}{l}\text { Ecluster_R cluster analy- } \\
\text { sis random selection }\end{array}$ & .11933174 & .18832392 & .1688660060 & .01822155366 & 3.28 \\
\hline $\begin{array}{l}\text { Ecommunity_S commu- } \\
\text { nity identified sensitive } \\
\text { selection }\end{array}$ & .12345679 & .21834060 & .1988776580 & .02175239724 & 5.97 \\
\hline $\begin{array}{l}\text { Ecluster_S cluster analy- } \\
\text { sis sensitive selection }\end{array}$ & .12224939 & .18315019 & .1712956940 & .01358339322 & 3.48 \\
\hline Asymptotic significance & .000 & & & & \\
\hline
\end{tabular}




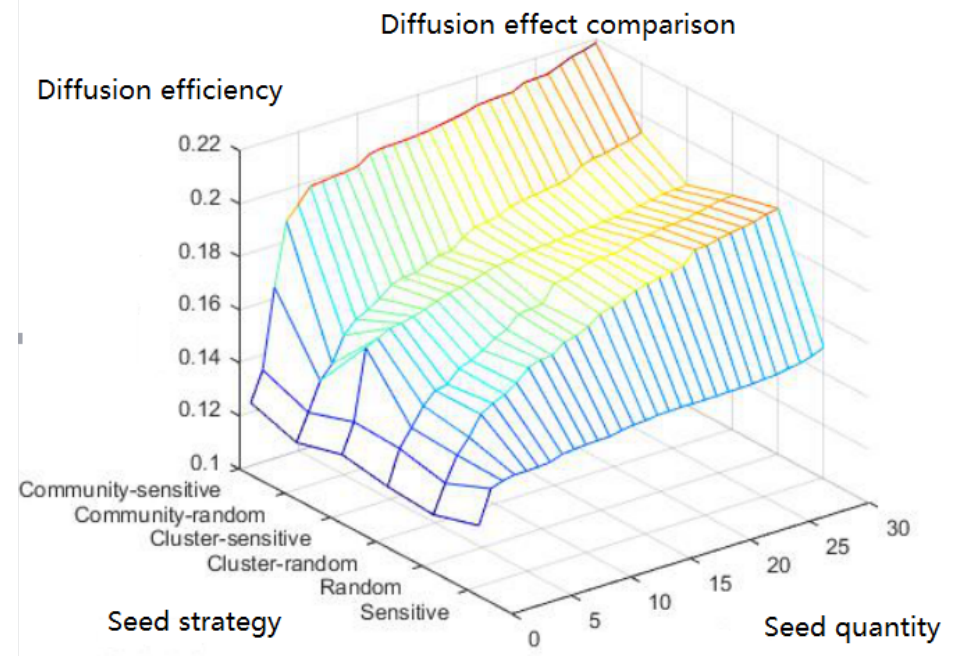

Fig. 7. Diffusion efficiency comparison for different seed strategies 1

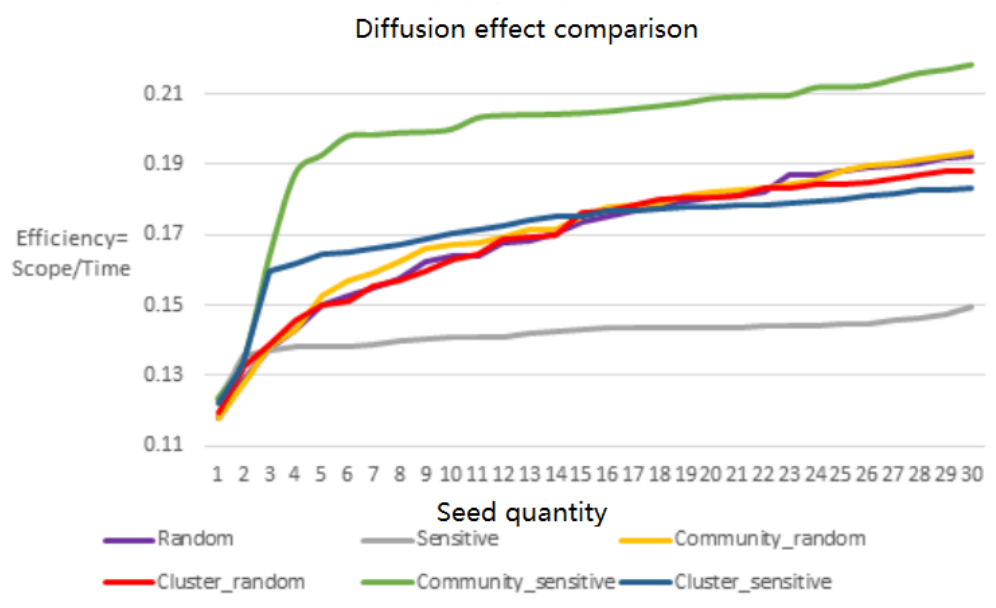

Fig. 8. Diffusion efficiency comparison for different seed strategies 2

In many relevant sample tests, the original hypothesis is significant at the $1 \%$ level, suggesting that there are significant differences in the six-point strategy efficiency. From the sample rank mean comparison results, the Ecommunity_S community identified sensitive selection $>$ Ecommunity_R community identification random selection $>$ Ecluster_S cluster analysis sensitive selection $>$ Ecluster_R cluster analysis random selection $>$ ER no partition random selection $>$ ES no partition random selection. In the present study, the communities' number is 8 . When the seed number is 8 , the differences among various selection strategies were the greatest, and the slopes of 
propagation efficiency and seed number in the community-sensitive selection strategy were the greatest.

Conclusion 3 after market segmentation (cluster analysis, community identification), and seed selection, which is more conducive to information dissemination. The seeds selected after community identification are more effective than those selected after cluster analysis. When the seeds number matches the communities, the community identification strategy can achieve optimal dissemination efficiency.

\section{Discussion and Inspiration}

This study selected the Sina Weibo network as a sample to study the seed strategies effect under different market segmentation mechanisms. According to the results, the number and quality of seed nodes are conducive to the network knowledge/information propagation. Market segmentation contributes to the knowledge/information propagation. Under the traditional market segmentation model, the seed strategy under the community identification model is superior to the seed strategy.

This study makes four contributions. First, community identification can serve as a method of market segmentation. Second, simply taking the seed sensitivity as a selection criterion has unideal dissemination effect, and the network location (community) should be fully considered. Third, in the cluster analysis, user social attributes (network level, activity level) were adopted as the criteria for classification, and the seed dissemination effect obtained by the user exhibits certain similarities to the seeds obtained by the community recognition. In the face of the high community identification cost, companies may consider adopting user social attributes as subdivision criteria rather than using community identification methods. Fourth, according to the difference in the seed number and the communication effect, when the seed number reaches $\mathrm{N}$ ( $\mathrm{N}$ denotes the number of communities), the transmission effect difference will be obvious. The community recognition description is the most efficient when selecting a seed in each community. With the continuous increase in the seed number, the differences in the different market segmentation methods effects will be reduced, which can be referenced by companies to control the seed number.

The text here has many deficiencies and requires further studies. Due to data limitation, this study selected more than 4000 nodes network and could not cover the entire network. In the subsequent studies, the data collection methods should be improved, and market segmentation and seed selection strategies should be considered across time and dynamic network environments.

\section{Acknowledgement}

This work is supported the following fund:

National natural science foundation : Research on panoramic and prescriptive marketing management and decision driven by big data in consumer mar- 
ket(NO:91746206);Omni Synchronous Marketing Paradigm in the Mobile Era: Tripartite Synchronous Interaction and Product-driven Integral Affect (NO:71672132).

\section{Reference}

[1] Garber T, Goldenberg J. From Density to Destiny: Using Spatial Analysis for Early Prediction of New Product Success. Marketing Science, 2004, 22(3):419-28. https://doi.org/10.1287/mksc. 1040.0051

[2] Haijian Li. Study on the Source of Enterprise value and its Theory. Chinese industrial economy, 2004, 3(3):52-60.

[3] William.D, john Na, Wurst. Advances in Market Segmentation. mariit'ting research, 2001, 4(5):15-30.

[4] Timothy B, Mark U. A Taxonomy of Differences between Consumers for Market Segmentation. International Journal ofbetweench in Marketing, 2002, 19(3):215-24. https://doi.org/10.1016/S0167-8116(02)00081-2

[5] Bennett L, Kittas A, Liu S, Papageorgiou LG, Tsoka S. Community structure detection for overlapping modules through mathematical programming in protein interaction networks. PLoS One, 2014, 9(11):1128-39. https://doi.org/10.1371/journal.pone.0112821

[6] Schulke C, Ricci Tersenghi F. Multiple phases in modularity-based community detection. Phys Rev E Stat Nonlin Soft Matter Phys, 2015, 92(4):2804-33. https://doi.org/10.1 103/PhysRevE.92.042804

[7] Bangming Xiao. Research on Network closure Mechanism of Transactional Community. Management science, 2015, 5(2):129-44.

[8] B.Q LI, Y.F LING, H.Y ZHANG, and S.Y ZHENG: The Design and Realization of Cherry Tomato Harvesting Robot Based on IOT. International Journal of Online Engineering, 12(12), 23-25, (2016). https://doi.org/10.3991/ijoe.v12i12.6450

[9] Feng Zhang. The interaction between Social Relations and Innovation ability on Service advantage. Journal of marketing science, 2016, 12(4):27-40.

[10] Minxue Huang. Talking about money or sentiment: how to Guide consumers to share their own Media Marketing. Psychology Journal, 2016, 2(2):211-20.

[11] Junyun Liao. Socialization Strategy of Virtual Brand Community members and its influence. nankai business review, 2016, 5(1):171-92.

[12] Hinz O, S B, Christian Barrot. Seeding Strategies for Viral Marketing: An Empirical Comparison. Journal of Marketing 2011, 75(2):55-71. https://doi.org/10.1509/jm.10.0088

[13] M H, B. L. Targeting Revenue Leaders for a New Product. Journal of Marketing, 2013, 77(3):65-80. https://doi.org/10.1509/jm.11.0428

[14] Kaibin He. The influence of Movie word of mouth on Box Office from the Perspective of dynamic Competition Theory. Journal of marketing science, 2016, 12(3):1-17.

[15] Goel S GDG. Predivting Individual Behavior with Social Networks. Markting Science 2013, 33(1):82-93. https://doi.org/10.1287/mksc.2013.0817

[16] Bass. a new product growth for model consumer durables the bass model. Management science, 2004, 50:1833-40. https://doi.org/10.1287/mnsc.1040.0300

[17] D K, J K, E $\square$ T. Influential nodes in a difiUsion model for soeial networks. ICALP, 2005, 2:1127-38.

[18] Garcia R. Uses of Agent-Based Modeling in Innovation/New Product Development Research. Journal of Product Innovation Management, 2005, 22:380-98. https://doi.org/10. 1111/j.1540-5885.2005.00136.x 
[19] Q DW, Z C, R LZ, W J. Efficient target strategics for contagion in scale-free networks. Physical review, 2005, 72:26-41.

[20] Nguyen D, Shi L. Competitive Advertising Strategies and Market-Size Dynamics: A Research Note on Theory and Evidence. Management Science, 2006, 52(5):965-73. https://doi.org/10.1287/mnsc.1060.0509

[21] .Delre S, Jager W, Bijmolt T, Janssen M. Targeting and timing promotional activities: An agent-based model for the takeoff of new products. Journal of Business Research, 2007, 68:826-35. https://doi.org/10.1016/i.jbusres.2007.02.002

[22] Lee. The role of consumers' network positions on information-seeking behavior of experts and novices: A power perspective. Journal of Business Research, 2012, 7(2):1-7.

[23] Libai A. Decomposing the Value of Word-of-Mouth Seeding Programs: Acceleration versus Expansion. Journal of Marketing Research, 2013, 4(2):161-76. https://doi.org/10. 1509/jmr.11.0305

[24] Kun Chen. Influence of Network Distribution of seed customer on Innovation Diffusion. management science, 2010, 23(1):38-51.

[25] Lans vd, R. v. B. G. A viral branching model for predicting the spread of electronic word of mouth. Marketing Science, 2010, 29(2):348-67. https://doi.org/10.1287/mksc. 1090.0520

[26] Fortunato S. Community detection in graphs. Physics Reports, 2010, 486(3-5):75-174. https://doi.org/10.1016/j.physrep.2009.11.002

[27] Yunpeng Zhao EL, and Ji Zhu. Community extraction for social networks. Proceedings of the National Academy of Sciences of the United States of America, 2011, 108 (18):73216. https://doi.org/10.1073/pnas. 1006642108

[28] I KAD, E GJ, T HJ. Experimental evidence of massive-scale emotional contagion through social networks. Proceedings of the National Academy of Sciences, 2014, 111(24):878890. https://doi.org/10.1073/pnas.1320040111

[29] B.Q LI, Y.F LING, M TIAN, and S.Y ZHENG: Design and implementation of sugarcane growth monitoring system based on RFID and ZigBee. International Journal of Online Engineering, 3(14), 96-106, (2018).

[30] J B. Word of mouth and interpersonal communication: A review and directions for future research. Journal of Consumer Psychology, 2014, 24(4):586-607. https://doi.org/10. 1016/j.jcps.2014.05.002

[31] JA C, D M. The effect of word of mouth on sales: online book reviews. Journal of Marketing Research, 2006, 43(3):345-54. https://doi.org/10.1509/jmkr.43.3.345

[32] M BR, J FC, J JJ. A 61-million-person experiment in social influence and political mobilization. Nature, 2012, 489(7415):295-8. https://doi.org/10.1038/nature11421

[33] Blondel V, Guillaume J, Lambiotte R. Fast unfolding of community hierarchies in large networks. Journal of Statistical Mechanics, 2008, 10(2):1000-15.

[34] Moreno Y. Dynamics of rumor spreading in complex networks. physical review, 2004, 7(6):163-80.

[35] Donald R L, Esteban-Bravo M. When giving some away makes sense to jump-start the diffusion process. Market Lett 2006, 17:243-54. https://doi.org/10.1007/s11002-006-7942-9

[36] Trusov M, V.Bodapati A. Determining Influential Users in Internet Social Networks. Journal of Marketing Research, 2010, 8(47):643-58. https://doi.org/10.1509/jmkr.47.4.643

[37] Mauro B, M. T. E, Dineli R.Mather. The Effects of the Social Structure of Digital Networks on Viral Marketing Performance. Information Systems Research, 2008, 19(2):283307.

[38] B.Q LI, S.Y ZHENG, M QIU: Research on Picking Identification and Positioning System Based on IOT. International Journal of Online Engineering, 7(14), 49-160,(2018). 
[39] Shujin Zhu. Research on Technology Diffusion and Absorptive capacity based on Cellular Automata. Theory and practice of system Engineering, 2006, 8(2):63-81.

[40] Linyuan Lu,Junan Lu. Complex network observation. Complex Systems and complexity Science, 2010, 9(3):173-86.

[41] Yu H, Hageman Blair R. A Framework for Attribute-Based Community Detection with Applications to Integrated Functional Genomics. Pac Symp Biocomput, 2016, 21(2):69-80. https://doi.org/10.1142/9789814749411 0007

[42] B.Q LI, M TIAN, S.Y ZHENG, and Y.F LING: Design and research of picking manipulator obstacle avoidance system based on IOT. International Journal of Online Engineering, 3(14), 96-106, (2018).

[43] Tao zhou. Opportunities and challenges in the study of complex Networks. Journal of University of Electronic Science and Technology, 2014, 43(1):1-5.

[44] Junan Lu. Some New advances in complex dynamic Network structure Identification. Complex Systems and complexity Science, 2010, 9(3):63-9.

[45] .Murphy A, Sewall. Market Segmentation Based on Consumer Ratings of Proposed Product Designs. Journat of Martceling Research, 1978, 4(11):557-64.

\section{$7 \quad$ Authors}

Zheng Shiyong (1983), come from Guilin, Guangxi province. $\mathrm{PhD}$ student, senior engineer, the main research direction for network marketing, IOT (e-mail: 29291838@qq.com).

Liu Mao-hong (1975), come from Wuhan, Hubei province. $\mathrm{PhD}$, professor, the main research direction for marketing. (E-mail: janliful@whu.edu.cn).

Huang Jin-de (1976), come from Tianlin, Guangxi province. Master degree,associate professor, the main research direction for signal and information processing.(e-mail: 229292710@qq.com).

Article submitted 2019-01-14. Resubmitted 2019-03-06. Final acceptance 2019-03-09. Final version published as submitted by the authors. 